\title{
Intralesional Rose Bengal in melanoma elicits tumor immunity via HMGB1
}

\author{
Hao Liu*, Krithika Kodumudi, Amy Weber, John Robinson, Satoshi Nemoto, Georgina Crago, Timothy McCardle, \\ Erica Royster, Amod A Sarnaik, Shari Pilon-Thomas \\ From 30th Annual Meeting and Associated Programs of the Society for Immunotherapy of Cancer (SITC 2015) \\ National Harbor, MD, USA. 4-8 November 2015
}

Intralesional (IL) therapy is under investigation to treat dermal and subcutaneous metastatic cancer. Rose Bengal (RB) is a staining agent that was originally used by ophthalmologists and in liver function studies. Previously, IL injection of RB induced regression of injected and uninjected tumors in murine models. However, the relevant mechanism is yet unknown. In this study, we used an OVA-expressing B16 melanoma murine model and found that IL RB treatment led to increased tumorspecific $\mathrm{T}$ cells with memory characteristics. CD8+ $\mathrm{T}$ cell are crucial for tumor-specific response elicited by IL RB. IL RB therapy also increased antigen-specific $\mathrm{T}$ cell proliferation and enhanced tumor regression. In addition, IL RB facilitated dendritic cells (DCs) infiltrating lymph nodes draining from tumor. Incubation of melanoma cells with RB led to necrosis and the release of High Mobility Group Box 1 (HMGB1), which activated DCs via up-regulation of CD40 expression. The blockade of HMGB1 significantly reduced the antigenpresenting ability of DCs. To determine whether this mechanism was relevant in patients treated with IL RB, we performed a pilot clinical study in melanoma patients (NCT01760499). IL RB led to tumor regression in both RB-injected and uninjected lesions, associated with an increase in circulating $\mathrm{T}$ cells. Increased tumorspecific response was found from those circulating T cells of 5 out of 7 tested patients after IL RB treatment. HMGB1 levels in patient sera were also elevated. Together, these results reveal a clinically relevant immunoadjuvant pathway triggered by tumor cell death secondary to ablation with RB.

\section{Trials Registration}

ClinicalTrials.gov identifier NCT01760499.
Published: 4 November 2015

doi:10.1186/2051-1426-3-S2-P408

Cite this article as: Liu et al:: Intralesional Rose Bengal in melanoma elicits tumor immunity via HMGB1. Journal for ImmunoTherapy of Cancer 2015 3(Suppl 2):P408.

H. Lee Moffitt Cancer Center \& Research Institute, Tampa, FL, USA

Submit your next manuscript to BioMed Central and take full advantage of:

- Convenient online submission

- Thorough peer review

- No space constraints or color figure charges

- Immediate publication on acceptance

- Inclusion in PubMed, CAS, Scopus and Google Scholar

- Research which is freely available for redistribution
() Biomed Central 